\title{
3 Research Square

\section{An innovative high frequency hyperthermia approach against SARS-CoV-2 and related virus: feasibility analysis}

Maria Alessandra Cutolo ( $\square$ maria.alessandra.cutolo@cerict.it )

University of Naples Federico II: Universita degli Studi di Napoli Federico II https://orcid.org/0000-00020004-8683

\section{Antimo Migliaccio}

University of Campania Luigi Vanvitelli: Universita degli Studi della Campania Luigi Vanvitelli

Lucia Altucci

University of Campania Luigi Vanvitelli: Universita degli Studi della Campania Luigi Vanvitelli

Antonello Cutolo

University of Naples Federico II: Universita degli Studi di Napoli Federico II

Andrea Cusano

University of Sannio: Universita degli Studi del Sannio

Research

Keywords: SARS-Cov, microwaves, hyperthermia

Posted Date: February 24th, 2021

DOI: https://doi.org/10.21203/rs.3.rs-231129/v1

License: (c) (1) This work is licensed under a Creative Commons Attribution 4.0 International License.

Read Full License 


\section{Abstract}

Heating is a strong enemy of SARS-CoV and related virus. Starting from both this consideration and from the basic principle of the microwave ovens which are based on the strong absorption, from organic tissues, of the radiation centered around $2.15 \mathrm{GHz}$, we examine the feasibility of using this frequency range to both lower the strength of the SARS-CoV (and related virus) inside the human body and to easily sterilize objects or closed rooms. We underline that this is only a preliminary theoretical feasibility analysis, which, of course, should be experimentally proven.

\section{Introduction}

It is well known that in many diseases like the one caused by COVID-19, the major damage arises from the antibody reaction generated to fight the virus itself. Many drugs have been demonstrated to be effective against these virus but at low infection levels. This means that, even only a decrease of the infection level might have beneficial results against this disease, particularly in the worst cases. On the other hand, hyperthermia can work well in many cases like, for instance, some kinds of cancer (1-4). On this line of argument, the idea of exploiting hyperthermia against COVID-19 to reduce its strength and the corresponding antibody reaction might be speculatively applied.

A profound difference arises between cancer and the COVID-19 case. In cancer, the illness is typically well localized, and this means that, in that area, temperatures higher than $50^{\circ} \mathrm{C}$ can be locally reached without inducing any relevant damage to the healthy tissues. With reference to this spatial distribution problem the second case looks totally different because the infected area coincides with the entire body with reference to the entire chest. Therefore, the operational temperature should be sufficiently high to reduce the infection level but sufficiently low to avoid any damage to any tissue. In addition, after checking if this condition can be fulfilled, a very precise temperature control of the inner tissues is required in order to avoid any negative collateral effect. Taking advantage on the strong absorption from the human tissues of radiation centered around $2,15 \mathrm{GHz}$ (microwave oven radiation) it seems reasonable to use this radiation to induce a well-controlled hyperthermia to decrease the virus strength. Therefore, we aim to analyze the feasibility of a microwave based approach against SARS-CoV-2 virus.

Thus, after some general considerations in Sec.2, we analyze the temperature influence on SARS-CoV-2 virus in sec. 3 and the temperature limits for human organs in Sec.4. Then, in Sec. 5 the main outlines of the potential approach coupled to a simple sensor for an accurate temperature control inside the body are discussed. Finally, the possibility of using this approach for a cheap sterilization of closed rooms are briefly analyzed.

\section{General Remarks}

2019-nCoV is a novel human coronavirus in addition to coronavirus 229E, NL63, OC43, HKU1, Middle East respiratory syndrome-related coronavirus (MERSr-CoV) and severe acute respiratory syndrome-related 
coronavirus (SARS-CoV). 2019-nCoV is an enveloped single-stranded plus stranded RNA virus with a diameter of 60-140 nm, spherical or elliptical in shape and pleomorphic. Zhao et al observed that angiotensin-converting enzyme 2 (ACE2) is the receptor for SARS-CoV-2. (5). In the normal human lung, ACE2 is expressed on both type I and II alveolar epithelial cells, up to $83 \%$ the type II alveolar cells expressing ACE2. Interestingly, men had higher ACE2 expression in their alveolar cells than women. This could explain the worse course of SARS-Cov2 syndrome in male subjects. The binding of SARS-CoV-2 on ACE2 causes an elevated expression of ACE2, which can lead to damages on alveolar cells. In most cases it appears that the alveolar cells damage act as an engine of further reactions leading even to the death. Wrapp et al reported that the receptor-binding ability of SARS-CoV-2 through its specific SPIKE protein is 10 to 20 times stronger than that of SARS-CoV (6). These features make 2019-nCoV a terrific threat for the whole mankind, which is fostering the efforts of many groups all around the world. Besides the attempts to find a radical solution like a vaccine, many attempts are under way to look for a suitable therapy.

An increasing body of evidence suggests that a subgroup of patients with severe COVID-19 develops a so-called "cytokine storm" syndrome, which plays a central role even in the respiratory failure from acute respiratory distress syndrome (ARDS), recognized as the leading cause of mortality in patients with COVID-19. The haemophagocytic lymphohistiocytosis (sHLH) is an hyperinflammatory syndrome resulting a sudden and fatal hypercytokinaemia which involves not only lungs and leads to multiorgan failure (7). The sHLH is characterized by high and unremitting fever, cytopenias, and hyperferritinaemia. The pulmonary involvement (mainly ARDS) is observed in more than $50 \%$ of patients, so that it is difficult discriminating whether the ARDS is a primary feature of COVID-19 or it should be considered as a severe sHLH consequence.

These patients present increased IL-2, IL-6 and IL-7, granulocyte CSF, interferon- $\gamma$ inducible protein 10, monocyte chemoattractant protein 1, macrophage inflammatory protein 1-a, and TNF-a. In particular, IL-6 and ferritin increase can be considered as predictors of fatality for COVID-19. Therefore, control of the hyper-inflammatory state together with reduction of viral load are issues of paramount importance for an effective therapy against COVID-19. In this regard the action of anti-inflammatory drugs deserves great consideration. The role of corticosteroids has been highly debated as during previous pandemics (SARS and MERS), were not routinely recommended and in the early protocols their use was also discouraged for COVID-19-associated lung injury. More recently, it has been reported that glucocorticoids could provide advantages in the COVID-19 treatment and their timely use might improve the early fever, promote the absorption of pneumonia and result in a better oxygenation.

Moreover, in hyperinflammation, immunosuppression is likely to be beneficial. Re-analysis of data from a phase 3 randomized controlled trial of IL-1 blockade (anakinra*) in sepsis, showed significant survival benefit in patients with hyperinflammation, without increased adverse events. Similarly, although controversial, using of tocilizumab (IL-6 receptor blockade) appeared to be effective in some, even severe cases of COVID-19 pneumonia associated with elevated IL-6 in China, and its use has been approved also in Europe. As concerns antiviral drugs effective in reducing the viral load, the use of remdesivir, a drug 
endowed with host polymerase selectivity against the Ebola virus, has been reported in some successful cases(8) but further investigation strongly reduced interest for this drug. Also, for Favipiravir, previously known as T-705, a prodrug of a purine nucleotide, favipiravir ribofuranosyl-5'-triphosphate, encouraging results have been reported but further investigation is needed before drawing conclusions on its efficacy (9).

We envisage that a combined therapy to decrease the viral load by physical methods in support of the pharmacological therapy used to manage ARDS and sHLH might represent an option. COVID-19 (and related viruses) start to lose their virulence when the environment temperature start overpassing $38^{\circ} \mathrm{C}$. Considering the literature, human organs might easily tolerate temperatures up to $44^{\circ} \mathrm{C}$ for up to 5 minutes. Thus, the idea of a therapy intrinsically based on a strictly controlled heating of the inner part of the human body at temperature around $42-44^{\circ} \mathrm{C}$ for short periods of times might represent an option. An example of localized treatment of the proposed approach is offered by the Herpes Zoster infection which is due to a virus for which any medical action is not radically efficient (10).

\section{The Temperature Limits For Sars-cov-2}

One of the first issues of this proposal is establishing which temperature and expo-sure time is necessary for inactivation of coronaviruses. A quite satisfactory bundle of data exists on human (Severe Acute Respiratory Syndrome [SARS] coronavirus and Middle East Respiratory Syndrome [MERS] coronavirus) or zoonotic coronaviruses and their inactivation by different temperatures used for thermal disinfection.

From most of the studies with original data it can be concluded that a thermal disinfection at $60^{\circ} \mathrm{C}$ for 30 $\min , 65^{\circ} \mathrm{C}$ for $15 \mathrm{~min}$ and $80^{\circ} \mathrm{C}$ for $1 \mathrm{~min}$ is effective to strongly reduce coronavirus infectivity by at least $4 \log _{10}$. The effect of heat can be due, as for other viruses, to protein denaturation induced by thermal aggregation of the SARS-CoV membrane protein (12). It was also shown that the nucleo-capsid protein of SARS-CoV is completely denatured in $10 \mathrm{~min}$ at $55^{\circ} \mathrm{C}(13)$. It is worth to note that all data described above were obtained with coronaviruses in suspension. Therefore, it cannot be ruled out that the results on dry surfaces might be different, although there is no reason to argue that it could be more stable. It would be interesting to assess whether the same temperature sensitivity is maintained even in the living organisms and how the temperature can affect other features, such as pathogenicity and spreading.

A recent study carried out in Wuhan (14) describes that 1 unit increase of temperature and absolute humidity were related to the decreased COVID-19 mortality at lag 3 and lag 5, respectively. Based on these findings, the temperature variation and humidity may significantly affect the COVID-19 mortality. This view is supported by several further reports (15), and this has left the room for the debate as to whether COVID-19 pandemic will be attenuated when the weather becomes warmer. This still remains an open issue. More interestingly, a study in elderly patients, which are at the highest risk of fatality, showed that fever was generally more prominent in surviving patients. This was likely due to the lower baseline body temperature frequently measured in elderly subjects which results in a lower maximum temperature of 
fever, so that lowering the threshold temperature for fever should be avoided in surveillance (16). These observations lead to probe the hypothesis that high temperature could be used to inhibit or weaken the virus spreading even in a living body and therefore, could represent an option for the adjuvant therapy of critical patients.

This prompt us to hypothesize using hyperthermia for therapy of several viruses including SARS-CoV-2. Two types of hyperthermia therapy could be considered. The whole-body and local hyperthermia therapy. The Whole-body hyperthermia therapy (WBHT) is the elevation of the core body temperature to 42 degrees. In vitro studies have shown that 42 degrees $C$ is cytocidal for virally infected lymphocytes of patients with AIDS, and even more effective when heating is repeated 4 days later. In particular, the patients have been submitted to low temperature WBHT for 1 hour at 40 degrees $\mathrm{C}$ and repeated 96 hours later, or high temperature WBHT for 1 hour at 42 degrees $C$ and repeated 96 hours later. In 1 year of follow-up after WBHT, there were positive effects of the therapy on frequency of AIDS defining events, Karnofsky score, and weight maintenance. Furthermore, two successive WBHT treatments were performed in four patients who were treated with protease inhibitor/triple drug therapy but with partially unsatisfactory response. In follow-up for 6 months, plasma HIV RNA and CD4 improved after WBHT, and these patients remained clinically well suggesting that WBHT may provide advantages in patients with suboptimal response to protease inhibitor therapy (17).

\section{The Hyperthermia And Human Organs}

Whereas there are several reports indicating that SARS-CoV-2 is very fleeting at temperature around $37^{\circ} \mathrm{C}$, especially wet environments, studies on virus stability in the living cells are substantially lacking.

Dewhirst et al. (18) provided an exhaustive report of the time-temperature damage threshold of the human organs, having shown that animal tissues can tolerate temperature of $43-43.5^{\circ} \mathrm{C}$ for several hours without irreversible damage. Successive studies carried out in pigs (19) demonstrated that blood heating to 45 and $48^{\circ} \mathrm{C}$ through an extracorporeal circulation device was effective in maintaining body temperature around $42-42,5^{\circ} \mathrm{C}$ without major damages in organs, including brain; a sever rhabdomyolysis, which was not described by other laboratories, was, instead, observed. However, the WBHT as well as the local hyperthermia are currently used as an adjuvant therapy against many cancers, to increase the cytotoxic effect of many chemotherapeutic agents. This pave the way to strategy of break down the virus aggressiveness by increasing temperature of the most affected tissues. Beside these desirable thermal effects on the virus, hyperthermia can induce pleiotropic effects that might be beneficial. At Fever-range of $39-42^{\circ} \mathrm{C}$, the whole body heating increases perfusion thereby lowering interstitial fluid pressure and reducing hypoxia in several tissues and tumor models. In addition, hyperthermia increases oxygenation via modulation of HIF-1 transcriptional activity. It was observed that hyperthermia activates the ERK pathway, with consequent increase of NADPH oxidase expression and activity (20). NADPH activity increases intracellular superoxide anions, which, in turn, lead to HIF-1 stabilization. In sum, hyperthermia lowers oxygen consumption by decreasing the mitochondrial membrane potential, thus improving overall oxygenation levels. Furthermore, hyperthermia strongly increases cytotoxic $T$ cell killing when applied in conjunction with a recombinant hyper-IL-6 fusion protein 
(H-IL-6). H-IL-6 is comprised of IL-6 and s-IL-6R. (21). Therefore, it is conceivable that hyperthermia, may contribute to reduce the release and need for circulating interleukins to exert cytotoxic effects on infected cells.

\section{The Basic Idea Of The Microwave Approach}

As pointed out in the previous sections, the mortality of Sars-CoV-2 and related virus rapidly increases when the temperature goes over $39^{\circ} \mathrm{C}$. This effect is accompanied by a reduction of the antibodies production, which is one of the major causes of death. On the other hand, it is also well known that human organs can support for short times temperature over $40^{\circ} \mathrm{C}$. The weakest organ is the brain. Its damage temperature is $42^{\circ} \mathrm{C}$ where other organs can reach $45^{\circ} \mathrm{C}$ for a limited time. Thus, to heat up the human body with a microwave beam to temperature lower than $45^{\circ} \mathrm{C}$ for a period up to some tens of minutes, might turn beneficial. Although it is presumable that this approach does not completely eliminate the virus population, a strong reduction could be hypothesized. This would also result in lowering the immune reaction, which is one of the main causes of death, even allowing the combined use of other therapies profiting of the low infection level. The exact values of both the operation temperature and the exposition time should be determined through an appropriate set of tests.

Indeed, the heating approach might be obtained in different ways among which we point to the following configurations. In the first example, a linear array of microwave sources (at $2.15 \mathrm{GHz}$ ) is used to make a scan of the body of the patient. The power of the beam and the scan velocity determine the temperature increase inside the body.

Another configuration can be attained by using a square array of microwave sources which irradiate all the body. The power of the beam and the exposure time determine the temperature increase of the body. In both cases the cooling time after the irradiation is of the order of a few minutes. Of course, to determine the values of the involved parameters to be used an appropriate research strategy and accurate settings are required.

The process must be accompanied by a precise temperature control of the inner temperature of the body. This might be achieved by taking advantage on a simplified version of the so-called 'Hospital in the Needle'. By combining nanophotonics, material science and optical fiber sensors (22-31), the Hospital in the Needle has been designed (27) in a configuration where a bunch of optical fibers can be integrated inside a needle. In the thinnest needle about ten optical fibers can be inserted, each of which is customized to perform a specific medical action. This is a strategy finalized to realize a single needle already shown to be able to perform in one shot all the following operations:

- Detection of cancer markers and miRNA

- High resolution localized ultrasound diagnostics integrated inside the needle

- Recognition of sick areas by linear and non-linear optical spectroscopy

- Ultrasound and laser surgery and ablation 
- Localized optically controlled drug delivery

- System for automatic guidance of the needle

For the optical fibers that carry out laser surgery, it is possible to consider the products already available on the market. All the other sensorized optical fibers are instead innovative devices, essentially based on an emerging technology in the field of optical fiber sensors called 'Lab-on-Fiber'. This technology involves the integration of optical fibers with materials defined on a micro- and nano-metric scale, which transform the simple fiber into an effective device capable of performing the aforementioned functions. The optical fiber, thanks to its intrinsic properties (small dimensions, flexibility, low weight, biocompatibility, etc.), is well suited to be inserted inside needles and catheters for medical use. Optical fibers, in addition to ensuring the transmission of light signals, can be sensorized by integrating components and functional materials, typically around their tip. The choice of the type and size of the integrated component / material clearly depends on the physical / chemical parameter to be detected. The use of optical fibers for the development of medical probes is a common practice. However, all the devices proposed so far are designed to perform the single function. In other words, sensorized optic fibers are integrated on the single needle or catheter for the single function, thus limiting the flexibility of use. Moreover, the approaches proposed so far concerning hybrid systems, based on different technologies for the development of multi-function probes, have given rise to rather bulky devices, whose dimensions limit their use only in some particular contexts. Consequently, the miniaturized and minimally invasive devices are mono-functional, since the multifunctional ones are more invasive and not very flexible so that they can be used only in well-defined application contexts. So far this precision medicine strategy has been demonstrated suitable in the following cases: detection of thyroid cancer markers $(25,26)$, loco regional anesthesia $(28,29)$, optically driven drug delivery (ref), localized ultrasound diagnostics $(30)$, optical activation of "optodrugs" and temperature control (22-24).

Accordingly, an optical fiber can be hosted inside a needle (a 26 gauge or even thinner needle is good enough) and it is possible to measure in this way the inner temperature of the body with an accuracy better than $0,1^{\circ} \mathrm{C}$. This can be easily made by inserting a temperature optical fiber sensor inside the needle. This solution allows to control the inner temperature of a body during the proposed treatment with a precision better than $0,1^{\circ} \mathrm{C}$ and with a very low invasiveness. In this way, a very thin needle (with a diameter smaller than one millimeter) can be used as a precise temperature sensor in order to keep under control the inner temperature of the body during the treatment thus avoiding any dangerous collateral effect.

More precisely the sensor is made by an optical fiber with its terminal part realized to be sensitive to the temperature. The termination of the fiber is provided by a temperature sensitive film or by a fiber bragg grating. Both the solutions have been showed suitable in a large variety of practical cases (REFS).

As a final remark, this approach might also be used for a fast, cheap and easy sterilization process. Nowadays sterilization involves either ultraviolet radiation or the use of a liquid disinfectants (e.g. Alcoholic solutions, quaternary ammonium derivatives). To sterilize a closed room, a simple nebulizer 
which injects in the room a mixture of simple water with sterilizing liquid might be proposed. Then, a small microwave source working at $2.15 \mathrm{Ghz}$ (the frequency of microwave ovens) might be applied. A room with a surface of $30 \mathrm{~m}^{2}$ and a height of a $3 \mathrm{~m}$ has a volume of $90^{\prime} \mathrm{m}^{3}$. In order to sterilize an environment like this about one liter of water would be needed. In SI units, $c_{s}=1.005+1.82 \mathrm{H}$ where $1.005 \mathrm{~kJ} / \mathrm{kg}{ }^{\circ} \mathrm{C}$ is the heat capacity of dry air, $1.82 \mathrm{~kJ} / \mathrm{kg}{ }^{\circ} \mathrm{C}$ the heat capacity of water vapor, and $\mathrm{H}$ is the specific humidity in $\mathrm{kg}$ water vapor per $\mathrm{kg}$ dry air in the mixture To bring this water at a temperature of about $60^{\circ} \mathrm{C}$ energy is needed. If the environment temperature is of about $20^{\circ} \mathrm{C}$ an energy of about 40.000 cal equivalent to about 160.000 joules should be provided. If we assume a microwave source of about 500 watts (typical sources for a small microwave oven), we see that we need about 5 minutes to sterilize a room like this. The sterilization is safe because the microwave radiation is fully absorbed by the vapor and the operator is on the back of the source in a totally safe position.

\section{Conclusions And Future Trends}

In this review we have critically approached the basis of a radically new approach against CORONA 19 and related virus. The next step should be a set of in vitro laboratory tests to check the validity and feasibility of the approach in vitro, before trying to extend its validation in in vivo models.

\section{Declarations}

- Ethics approval and consent to participate This point does not apply to our case as we do not perform any experiment on either alnimals or human beings.

- Consent for publication

All the authors give their own consent for publication of this paper.

- Competing interests

There is not competing interest between the content of this paper and anyone of the authors.

- Funding

There is no specific funding on this research. It has been developed outside of any of the research projects on which anyone of the authors is actually involved.

- Authors' contributions Antonello Cutolo and Andrea Cusano had the the basic idea discussed in the paper. Maria Alessandra Cutolo worked out the feasibility Antimo Migliacco and Lucia Altucci have performed all the medical analysis.

- Acknowledgements Non acknowledgement is present. 
- Availability of data and material

All the materiali contained in this papere cannot be made available before publication.

\section{CONFLICT OF INTEREST DECLARATION}

By the present, we declare that no authors has any conflict of interest between his scientific and institutional activities and the results discussed in the enclosed paper An innovative high frequency hyperthermia approach against SARS-CoV-2 and related virus: feasibility analysis by Antonello Cutolo, Antimo Migliaccio, Lucia Altucci, Maria Alessandra Cutolo, Andrea Cusano, which is submitted for publication on Medical Hypotheses.

Napoli December 9th 2020

The corresponding author

\section{Maria Alessandra Cutolo}

\section{References}

1. CSSR Kumar, F Mohammad (2011) Magnetic nanomaterials for hyperthermia-based therapy and controlled drug delivery- Advanced drug delivery reviews, 63, 789-808

2. Johannsen, B. Thiesen, P. Wust \& A. Jordan(2010)Magnetic nanoparticle hyperthermia for prostate cancer, International Journal of Hyperthermia,26:8,790-795,DOI:10.3109/02656731003745740

3. Hurwitz, M.D., Hansen, J.L., Prokopios-Davos, S., Manola, J., Wang, Q., Bornstein, B.A., Hynynen, K. and Kaplan, I.D. (2011), Hyperthermia combined with radiation for the treatment of locally advanced prostate cancer. Cancer, 117: 510-516. doi:1002/cncr.25619

4. Mahmood, J.; Shukla, H.D.; Soman, S.; Samanta, S.; Singh, P.; Kamlapurkar, S.; Saeed, A.; Amin, N.P.; Vujaskovic, Z. (2018) Immunotherapy, Radiotherapy, and Hyperthermia: A Combined Therapeutic Approach in Pancreatic Cancer Treatment. Cancers, 10, 469.

5. . Y Wang, Y Wang, W Luo, L Huang, J Xiao, F Li, et al. A comprehensive investigation of the mRNA and protein level of ACE2, the putative receptor of SARS-CoV-2, in human tissues and blood cells. J Med Sci. 2020; 17(11): 1522-1531. Published online 2020 Jun 18. doi: 10.7150/ijms.46695

6. Ismail, A.M., Elfiky, A.A. SARS-CoV-2 spike behavior in situ: a Cryo-EM images for a better understanding of the COVID-19 pandemic. Sig Transduct Target Ther 5, 252 (2020). https://doi.org/10.1038/s41392-020-00365-7

7. Cavalli G, De Luca G, Campochiaro C, Della-Torre E, Ripa M, Canetti D, Oltolini C, Castiglioni B, Tassan Din C, Boffini N, Tomelleri A, Farina N, Ruggeri A, Rovere-Querini P, Di Lucca G, Martinenghi S, Scotti R, Tresoldi M, Ciceri F, Landoni G, Zangrillo A, Scarpellini P, Dagna (2020) Interleukin-1 blockade with high-dose anakinra in patients with COVID-19, acute respiratory distress syndrome, and hyperinflammation: a retrospective cohort study. Lancet Rheumatol. Jun;2(6): e325-e331. doi: 10.1016/S2665-9913(20)30127-2. Epub 2020 May 7. 
8. Dolin R and Hirsch MS (2020) Remdesivir - An Important First Step. N. Engl. J. of Medicine https://doi.org/10.1056/NEJMe2018715

9. Q Cai, M Yang, D Liu, J Chen, D Shu, J Xia, X Liao, Y Gu, Q Cai, Y Yang, C Shen, X Li, L Peng, D Huang, J Zhang, S Zhang, F Wang, J Liu, L Chen, S Chen, Z Wang, Z Zhang, R Cao, W Zhong, Y Liu, L Liu, (2020) Experimental Treatment with Favipiravir for COVID-19: An Open-Label Control Study, Engineering, https://doi.org/10.1016/j.eng.2020.03.007

10. Systemic hyperthermia in the treatment of HIV-related disseminated Kaposi's sarcoma. Long-term follow-up of patients treated with low-flow extracorporeal perfusion hyperthermia. Alonso K, Pontiggia P, Sabato A, Calvi G, Curto FC, de Bartolomei E, Nardi C, Cereda P. Am J Clin Oncol. 1994 Aug;17(4):353-9.

11. Effect of different human tissue processing techniques on SARS-CoV-2 inactivation-review. Paggiaro AO, Carvalho VF, Gemperli R. Cell Tissue Bank. 2020 Oct 8:1-10. https://doi.org/10.1007/s10561-02009869-6.

12. Lee YN, Chen LK, Ma HC, Yang HH, Li HP, Lo SY. (2005) Thermal aggregation of SARS-CoV membrane protein. Journal of Virological Methods; 129:152e61

13. Wang Y, Wu X, Wang Y, Li B, Zhou H, Yuan G, et al. (2004) Low stability of nucleocapsid protein in SARS virus. Biochemistry; 43:11103e8

14. YMa, Y Zhao, J Liu, X He, B Wang, S Fu, J Yan, J Niu, J Zhou, B Luo, Effects of temperature variation and humidity on the death of COVID-19 in Wuhan, China, Science of The Total Environment,724, (2020),138226, ISSN0048-9697, https://doi.org/10.1016/j.scitotenv.2020.138226.

15. A Briz-Redón, Á Serrano-Aroca, A spatio-temporal analysis for exploring the effect of temperature on COVID-19 early evolution in Spain, Science of The Total Environment, 728, (2020), 138811, ISSN 0048-9697, https://doi.org/10.1016/j.scitotenv.2020.138811.

16. Leung (2020) Risk factors for predicting mortality in elderly patients with COVID-19: A review of clinical data in China. Mechanisms of Ageing and Development, V188, 111255

17. Ash Stephen R.; Steinhart, C. R.; Curfman, M. F.; Gingrich, C. H.; Sapir, D. A.; Ash, E. L.; Fausset, J. M.; Yatvin, M. B. (1997) Extracorporeal whole-body hyperthermia treatments for HIV infection and AIDS. ASAIO Journal: September-October 1997 - p M8389

18. W. Dewhirst, B. L. Viglianti, M. Lora-Michiels, M. Hanson \& P. J. Hoopes (2003) Basic principles of thermal dosimetry and thermal thresholds for tissue damage from hyperthermia, International Journal of Hyperthermia, 19:3, 267-294

19. Lassche, T. Frenzel, MH. Mignot, MA Jonkel, JG van der Hoeven, CML van Herpen, GJ Scheffer (2020) Thermal distribution, physiological effects and toxicities of extracorporeally induced wholebody hyperthermia in a pig, Physiological Reports. 2020;8: e14366

20. Jung Moon, P. Sonveaux, PE. Porporato, P. Danhier, B. Gallez, I. Batinic-Haberle, Yu-Chih Nien, T. Schroeder, and MW. Dewhirst. (2010) NADPH oxidase-mediated reactive oxygen species production activates hypoxia-inducible factor-1 (HIF-1) via the ERK pathway after hyperthermia treatment. Proc. Natl. Acad. Sci. USA, 107 (47) 20477-20482; https://doi.org/10.1073/pnas.1006646107 
21. Fisher DT, Chen Q, Skitzki JJ, Muhitch JB, Zhou L, Appenheimer MM, et al. (2011). IL-6 transsignaling licenses mouse and human tumor microvascular gateways for trafficking of cytotoxic $T$ cells. J Clin. Invest; 121:3846-5

22. "Photonics for safety and security, A.Cutolo, A.G.Mignani, A.Tajani Eds., World Scientific Publishing Company, Singapore (2014) ISBN: 978-981-4412-96-4

23. "An Introduction to optoelectronic sensors", G.Righini, A.Tajani, A.Cutolo Eds., World Scientific Publishing Company, Singapore (2009) ISBN 13-978-981-283-412-6

24. "Optochemical Nanosensors",Edited by A. Cusano, F. Arregui, M. Giordano, A. Cutolo, Taylor \& Francis November 2012, ISBN: 1439854890.

25. Quero, G., Consales, M., Severino, R., Vaiano, P., Boniello, A., Sandomenico, A., Ruvo, M., Borriello, A., Diodato, L., Zuppolini, S., Giordano, M., Nettore, I.C., Colao, A., Macchia, P.E., Santorelli, F., Cutolo, A., Cusano, A., High sensitive long period fiber grating biosensor for cancer biomarker detection, (2016), HEALTHINF 2016 - 9th International Conference on Health Informatics, Proceedings; Part of 9th International Joint Conference on Biomedical Engineering Systems and Technologies, BIOSTEC 2016, pp. 561-569.

26. Quero, G., Severino, R., Vaiano, P., Consales, M., Ruvo, M., Sandomenico, A., Borriello, A., Giordano, M., Zuppolini, S., Diodato, L., Cutolo, A., Cusano, A., High sensitive reflection type long period fiber grating biosensor for real time detection of Thyroglobulin, a differentiated thyroid cancer biomarker: The "Smart Health" Project, (2015) Proceedings of SPIE - The International Society for Optical Engineering, 9634, art. no. $96342 \mathrm{G}$.

27. Cutolo, A.Cusano, M.Consales, M. Pisco, M.Consales, A. Aliberti, A.Ricciardi, Ago o catetere provvvisto di una pluralità di fibre ottiche, Italian Patent N.102019000005362, filed April 8th 2019

28. Carotenuto, A Micco, A. Ricciardi, E. Amorizzo, M. Mercieri, A. Cutolo, A. Cusano, (2017) Optical Guidance Systems for Epidural Space Identification, IEEE Journal of Selected Topics in Quantum Electronics, 23,2, 1-9 (invited Paper)

29. "Optical Fiber Technology enables Smart Needles for Epidurals: in-vivo swine study" B, Carotenuto, A. Ricciardi, A. Micco, E. Amorizzo, M. Mercieri, A. Cutolo, and A. Cusano, Biomed. Opt. Express 10, 1351-1364 (2019)

30. Giaquinto, A Ricciardi, A. Cutolo, A.Cusano, (2016) Lab on Fiber Plasmonic Probes for Ultrasound detection: A comparative study, IEEE J. Lightwave Technology, 34,22, 5189-98

31. Principe, M. Giaquinto, A. Micco, M.A. Cutolo, M. Riccio, G.Breglio, A.Irace, A.Ricciardi, A.Cusano, Thermo-plasmonic lab-on-fiber optrodes, Optics \& Laser Technology, 132, 106502 (2020)

\section{Figures}




\section{OUR IDEA: THE HOSPITAL IN THE NEEDLE}

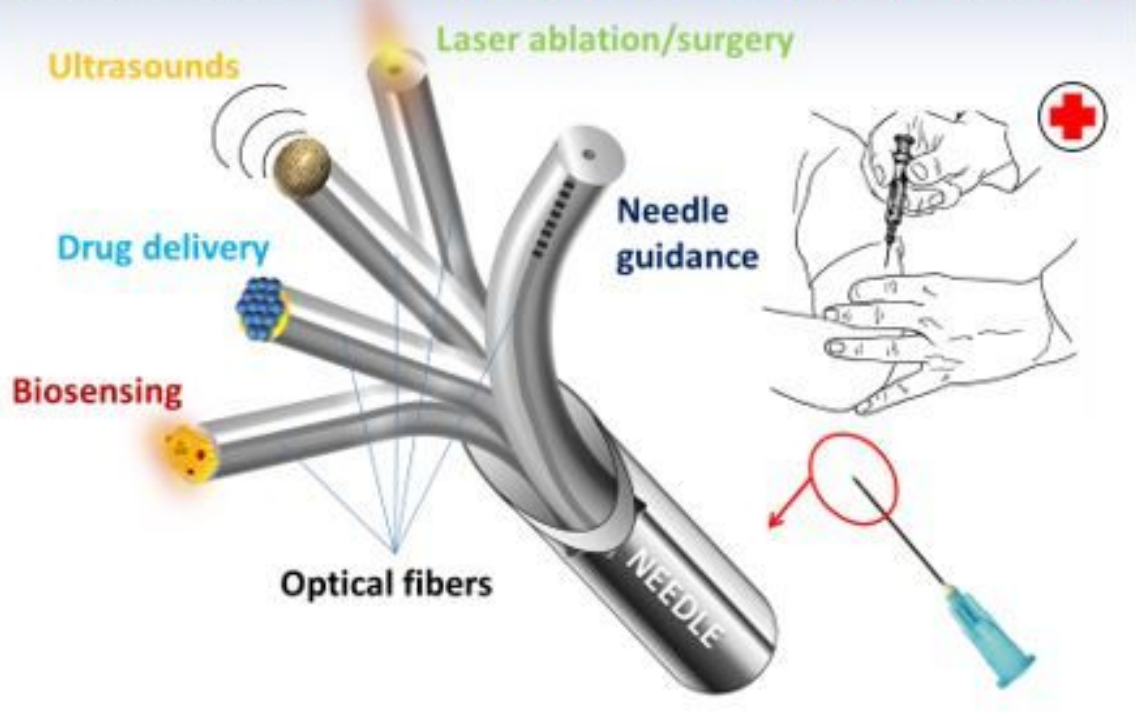

\section{Figure 1}

Schematic of the hospital in the needle. A bunch of optical fiber is integrated inside a needle in order to simultaneously perform a set of different diagnostic and therapeutic item after an appropriate functionalization of each of them. 